Uşak Üniversitesi Sosyal Bilimler Dergisi

$2015,8 / 2$

\title{
Türk Devlet Kültüründe Rüya
}

Savaş KURT*

Beyza KURT*

\section{Öz}

Araştırmada devlet geleneğinde güçlü bir birikime sahip olan Türk milletinin bu yapılanmasında rüyaların yeri ve önemi üzerinde durma ayrıca Türk kültür hayatında rüyanın insan hayatını nasıl yönlendirdiği üzerinde durulmuştur. Araştırmaya İslamiyet öncesi Türk devlet anlayışında rüyanın önemi üzerinde durularak başlanmıştır. Çeşitli Türk devletlerinin kuruluşu ya da rüya merkezli yaşananlarla birlikte Osmanlı devlet geleneğinde rüya anlayışına temas edilmiştir. Görülen rüyanın insan hayatı üzerinde etkilerine değinilerek rüyayı gören kişinin siyasi görevi de düşünülerek rüyalara getirilen yorumlar ele alınmıştır.

Anahtar Kelimeler: Devlet, Destan, Rüya, Motif, Yorum.

\section{The Dream in the Turkish Government Tradition}

\section{Abstract}

In this study, it was emphasized on the place and importance of dreams that have a strong erudition on government tradition of Turkish Society and how affected person's life by dreams in Turkish culturel life. The research was started by emphasizing the importance of dreams in preIslamic Turkish government tradition. It was mentioned to perception of dreams in Ottoman government tradition with foundation of various Turkish governments or thing that existed centre point of dreams. By mentioning the effects of dreams on person's life, it was handled the interpretations on dreams by the person who had a dream depending his political position.

Key Words: Government, Epic, Dream, Motif, Interpretation.

\footnotetext{
* Çanakkale On Sekiz Mart Üniversitesi, Türk Dili ve Edebiyatı ABD, Doktora Öğrencisi

* Çanakkale On Sekiz Mart Üniversitesi, Türk Dili ve Edebiyatı ABD, Doktora Öğrencisi
} 


\section{Giriş}

Devlet sözcügünün dilimize Arapçadan geçtiği bilinmektedir. Devlet ya da "dûlet" sözcükleri "değişmek, bir hâlden başka hâle dönmek, birbiri ardınca nöbetleşe gelmek, zafer kazanmak," anlamlarına gelir. Devlet, belli sınırlar içindeki insan topluluğuna ait siyasî hâkimiyetin teşkilatlanmış şeklidir (İslâm Ansiklopedisi, 1994: 234-236). Devlet, düzenli ve teşkilatlanmasını sağlamış bir insan topluluğu olarak da tanımlanabilir. Devleti meydana getiren insan faktörü, insan topluluklarının belki de en gelişmiş olanıdır.

Türklerde devlet kurma geleneği eski dönemlere kadar götürülebilmektedir. Özgürlük ve bağımsızlık noktasında hassaslıklar göz önüne alındığında Türk milletinin bu konuda önemli bir noktada olduğu söylenebilir. Kurdukları devletlerin hemen hepsinde temel amacın özgürce yaşamak ve ardından dünya hâkimiyeti kurmak ideali olarak değerlendirildiğinde kuşkusuz bu kabulün sosyal, hatta dinsel hayata kadar yansımaları görülebilecektir.

Devlet geleneğinde sosyal olayların etkisinin olduğu kaçınılmaz bir olgudur. Bu açıdan bakılacak olursa sosyal hayat içerisinde rüya görme, görülen rüyanın tabiri hususlarının devlet geleneğinde de sosyal hayatta da önemli yerinin olduğu görülmektedir. Bu çalışmada devlet kültürünün oldukça eskilere dayandırıldığı Türk devlet sistemi içerisinde görülen rüyalar ve bunlara bağlı olarak gerçekleşen hadiseler üzerinde durulmaya çalışılacaktır.

\section{Haberci Rüya}

Türkçe sözlükte, gerçekleşmesi beklenen ve istenen şey, umut, gerçekleşmesi olanaksız durum, hayal (Türkçe Sözlük, 2007: 226), olarak açıklanan rüya; uykunun genel ve karakteristik özelliklerinden biri olmakla birlikte, yine uykunun canlıda oluşturduğu hızlı göz hareketleriyle yakından ilişkili bulunan, görsel ve duyuşsal alg1 ve duygulara verilen isim olarak açıklanmaktadır.

Rüya, kuşkusuz, hayatımızın bir parçasıdır. Tüm insanlar rüya görür ve gördüğü rüyayı birçok şekilde yorumlar; kimi önemli bulur, kimi önemsemez. Birçok kişi rüyada gördüğünü kendisi için haberci olarak yorumlamaktadır. Rüyada bazı şeylerin kişiye doğrudan gösterildiğine inanılırken bazılarının da çeşitli işaretlerle anlatıldığı düşünülür (Gündüz, 2009: 22). 


\section{Rüya Motifi}

Halk kültürü açısından bakıldığında rüya; destan, halk hikâyesi, masal, efsane gibi anlatım türlerinde yer alan ve gelecekte olacakların işaretlerini verebilen motif olarak tanımlanmaktadır. Rüyalarla, yaşama biçimi, hayat tarzı, beklenti ve hayata bakış arasında önemli bir bağ vardır. Hele bazı rüyalar vardır ki, bunlar asırlar boyu sürecek bir serüvenin başlangıcını belirler mahiyettedir. Bu yüzden olsa gerek Anadolu'nun birçok bölgesinde; "düş olmadan iş olmaz," diye bir deyiş kullanılmaktadır.

Halk hikâyelerinde ve âşık edebiyatında yer alan rüya motifiyle kahramanın sanatçı kişiliği belirlenir. Rüyayı gören kişi rüyasında bade içer ve kendisine gösterilen kıza âşık olur. Uyandığında ilk deyişini söyler ve böylelikle sade kişilikten sanatçı kişiliğe geçmiş olur (Kaya, 2007: 621).

\section{Devlet Geleneğinde Rüya}

Rüyaya, Türk devlet kültürü açısından bakıldığında; Göktürkler, Oğuz Kağan, Göç, Dede Korkut, Osmanlı Devleti gibi önemli ürün ve dönemlerde karşımıza çıkmakta, hadiselerin incelenmesinde, gelişmesinde ve tamamlanmasında önemli roller üstlenmektedir. Kahramanın gördüğü rüya, birileri tarafından yorumlanır ve bu yorum doğrultusunda olaylar cereyan eder.

Göktürkleri Çin esaretinden kurtararak istiklallerine kavuşturan Liyao-Yuen-Hay'ın babası Pao, oğlunun doğumu hakkında şöyle bir rüya görür:

Pao bir gün Tanrı'nın kendisine bir erkek evlat vermesi için dua eder. Bu sırada gözüne tepesinde iki boynuzu bulunan büyük bir balık görünür. Bu tuhaf balık kurban kesilen yere yaklaşır ve bir süre sonra kaybolur.

Yorumcular Pao'nun rüyasını uğurlu bir rüya sayarlar. Ertesi akşam karısı da aynı balığı adam şeklinde, elinde bir şey tutmuş olarak görür. Bu yaratık elindeki parlak şeyi kadına verir ve bir oğlu olacağını müjdeler. Kadın uyanır uyanmaz gördüğü rüyayı kocasına anlatır. Pao, eşine üç nesil sürecek torunları olacağını, anasının kendisine söylediğini hatılayarak, bu rüyaların uğurlu bir oğlu olacağına alamet olduğunu söyler. Yuen-Hay üç ay sonra doğar. Doğduğu zaman sol elinde Yuen-Hay yazılı olduğu görülür. Bunun üzerine kendisine bu isim verilir (Uraz, 1967: 188-189).

Pao, gördüğü rüyayı bir müjde olarak algılar ve gelecekte Göktürkleri Çin esaretinden kurtaracak olan Yuen-Hay'ın doğacağı ve daha sonra üç nesil devam edecek olan hanlığın kendi ailesinden olacak olmasına sevinir. 
Rüyalar, destan kahramanlarının hareket tarzlarının tayinine ve gelecekteki olaylardan haberdar olmalarına yaraması bakımından destanlarda önemli yer tutmaktadır.

Türk kültürünün ürünlerinden olan destanlarda rüya motifine Oğuz Kağan Destanı'nda Uluğ Türk tarafından görülen rüyada rastlamaktayız. Oğuz Kağan Destanı'nda, Oğuz Kağan'ın veziri Uluğ Türk, rüyasında: Altın bir yayın gün doğusundan gün batısına; üç gümüş okunsa kuzeye doğru gittiğini görür. Bu rüyasını Oğuz Kağan'a anlatırken de; Gök Tanrı düşümde gördüğümü hakikate çıarsın! Tanrım bütün yeryüzünü senin soyuna bağışlasın, diye dua eder. Oğuz Kağan, Uluğ Türk'ün rüyasını ve yorumunu çok beğenir. Onun ögütleri üzerine oğullarını çağırarak gönlünün av istediğini söyler. Gün, Ay ve Yıldız'ı gün doğusuna; Gök, Dağ ve Deniz'i de gün batısına gönderir. Gün, Ay ve Yıldız, bu yolculukta pek çok av avladıktan sonra buldukları altın bir yayı babalarına getirirler. Oğuz Kağan çok sevinir ve yayı üçe bölerek onların da yay gibi olmalarını, okları göklere atmalarını ögütler. Diğer yandan Gök, Dağ ve Deniz de yine pek çok av avladıktan sonra yolda üç gümüş ok bulurlar. Buldukları bu okları tıpkı diğer kardeşleri gibi babalarına verirler. Oğuz Kağan, okları üçe bölüp küçük oğullarına verirken, yayın oku atacağını ve onların da oklar gibi olmaları gerektiğini söyler (Sepetçioğlu, 1995: 145). Bu rüya Oğuz boylarının geleceği ve devlet teşkilatlanması hakkında bir ön haber niteliğindedir. Uluğ Türk'ün rüyasıyla, Oğuz Han bir nevi büyük devlet olmanın temellerini atmıştır.

Göç Destanında Uygur kağanı Böğü Kağan uyurken, penceresinin önünde bir kız hayali belirir, onu uyandırır. Böğü Kağan çekinir, kızı görmemiş gibi davranır, kendisini uykudaymış gibi gösterir. İkinci gece kız yine gelir. Böğü Kağan, yine görmüyormuş gibi yapar, kendisini uykuda gösterir. Sabah olur. Kağan, vezirine danışır. Üçüncü gece kız yine gelir. Böğü Kağan, vezirinin öğüdüne uyarak kızı alıp Ak-Dağ'a gider. Böğü Kağan ile kız bu dağda gün doğana kadar konuşurlar. Yedi yıl, altı ay, yirmi iki gün her gece kız, Böğü Kağan'a gelir; her gelişinde de ona dünyanın efendisi olacağını söyler. En sonunda Kağan uyanınca ordusunu toplar kardeşlerini çeşitli ülkelere seferler yapmak üzere ordunun başına geçirir. Kardeşleri dört bir yana seferler yaparlar ve Orhun vadisini ganimetlerle doldururlar.

Bir müddet sonra Böğü Kağan bir rüya daha görür. Bu kez rüyasında ak giysilere bürünmüş, başında ak bir şerit, elinde de çam kozalağı büyüklüğünde Yada taşı olan yaşlı biri vardır. Yaşlı kişi Böğü Kağan'a yaklaşır, Yada taşını Böğü Kağan'a verir ve şöyle der: “Bu taşı saklarsan dünyanın dört bucağın milletinin buyruğu altına alırsın. O gece Bö̆̆̈̈ 
Kağan'ın baş veziri de aynı rüyayı görmüştür. Bunun üzerine Böğü Kağan uyanır uyanmaz ordularını toplar. Batı yönüne sefere çıkar, pek çok ülke fetheder ve birçok milleti buyruğu altına alır (Sepetçioğlu, 1995: 126-131)".

Göç Destanı'nda anlatılan bu hadiselerdeki Böğü Kağan gördüğü her iki rüyanın da gelecekten haber verme niteliğinde rüyalar olduğu görülmektedir. Devletin genişlemesinde önemli bir dayanak noktası Kağan'a gösterilen rüyalar olarak kabul edilmektedir. Kağan, rüya yorumlarından güç alarak ülkesinin sınırlarını genişletir.

Manas Destanı'nda Kanıkey, Manas'ın esir düştüğü gece rüya görür; Avucu yanmakta, gözü seğirmektedir. Bundan Manas'ın ölümcül bir yara aldığını anlar. Manas'ın son seferinde yine Kanıkey rüyasında, Manas'ın tahtının ayaklarının kırıldığını görür ve felaketi anlar. Manas'ın yakın dostu ve savaşçısı Almambet, Manas'a katılmadan önce Manas bir rüya görür ve bu rüya üzerine yapılanlar destanda şu şekilde verilir:

Er-Manas, gecelerden bir gece bir rüya görür. Oturup etleri şişlere dizip ateş üzerinde pişirip kızartırken birdenbire dizildiği demir şişler tutuşup yanmaya başlar. Şişler yanarken Manas uyanır. Bu rüyaya bir türlü anlam veremez. Düşünür, düşünür. Kırk yiğidini toplar. Onlara sorar, onların rüyasını tabir etmesini ister; ama hiçbiri görülen rüya hakkında bir şey söyleyemez. Rüyayı hiç kimse tabir edemediğinden toylar yapılıp şölenler verilir; bu rüyayı tabir edene çok mal verileceği duyurulur. $\mathrm{Bu}$ toylardan da bir sonuç çıkmayınca rüya Kara Han'ın oğlu Almambet'in kendi hizmetine geleceği şeklinde yorulur ve bu yorum da doğru çıkar.

Dede Korkut Kitabı'ndaki Salur Kazan'ın Evinin Yağmalanması hikâyesinde; Salur Kazan Han, ava çıktığı günün gecesinde rüyasında bir karabasan görür. Kara kuduz kurtlar, karakargalar hep hanesine saldırıyordur. İçi rahat etmez. Adamlarını av yerinde bırakıp, atına atlayarak, üç gün yol giderek obasına varır. Durumu görünce, kanlı gözyaşları döker. Sonra da kâfirlerin peşine düşer (Gökyay, 2006: 208). Bu rüyada da görmekteyiz ki Salur Kazan gördüklerine kötü dahi olsa bir anlam yüklemiş ve rüyasının peşinden giderek gördüklerinin gerçekliğe dönüşmesine şahit olmuştur.

Osmanlı Devleti'nin kuruluşu ile ilgili rüya motifi ise şu şekildedir: Osmanlı Devleti'nin kurucusu Osman Bey, Şeyh Edebali'yi ziyarete gidip öğütlerini dinler. Misafir olarak kaldığı bir gece şöyle bir rüya görür; Şey Edebali'nin koynundan çıkan bir ay gelir kendi koynuna girer. Göğsünden bir ağaç büyümeye başlar. Öylesine büyük bir ağaç olur ki dalları gökleri, kökleri tüm dünyaya sarar. Gölgesi bütün yeryüzünü tutar. İnsanlar o ağacın gölgesinde toplanırlar. Ulu dağlara ve dağların eteğinden çıan coşkun sulara hep o ağaç gölge eder. 
Osman Bey rüyasını Şeyh Edebali'ye anlatır. Edebali rüyayı şöyle yorumlar: "Oğul Osman, Hak Teâla sana ve soyuna hükümranlık verdi mübarek olsun, kızım Malhun Hatun senin helâlin olsun (Âşıkpaşaoğlu Ahmed Âşıkî, 1949: 95)" der.

Bu rüyadan sonra, kurulan Osmanlı Devleti tam 6 asır Devlet-i Muazzama olarak üç kitada hüküm sürer.

Yavuz Sultan Selim'in hizmetlerinde çalışan Hasan Ağa'nın gördüğü rüya üzerine Hasan Ağaya rüyada gördüğü Hulefa-i Raşidin; Selim Han kalkıp gelsin, Mekke ve Medine'nin hizmeti ona verildi, demiştir. Bu rüyadan dolayı Yavuz Sultan Selim Mısır seferine Allah Resulü'nün davetlisi olarak çıktığını belirtmektedir.

Sultan Ahmet, bir gün rüyasinda (http://www.sultanahmetcami .org/sultan-1-ahmedin-ayasofya--ziyaretleri_h 57.html); Avusturya kralı ile güreşe tutuştuğunu, sırtüstü yere düştüğünü ve sırtının toprağa yapıştığını görür. Ürpererek uyanır, çok heyecanlanır ve üzülür. Rüyanın genel görünüşü korkutucudur.

Saraya tabirciler davet edilir. Fakat rüyaya yapılan tabirler, I. Sultan Ahmet'i tam olarak tatmin etmez. Devletin ileri gelenleri, Sultan I. Ahmet Han'a, bu rüyayı bir kere de Üsküdar'da bulunan Şeyh Aziz Mahmut Hüdai Hazretlerine tabir ettirmesini tavsiye ederler. I. Ahmet Han, bir mektup yazarak rüyasını Hüdai Hazretlerine arz eder.

Haberci, mektubu alıp süratle Üsküdar'a geçer. Aziz Mahmut Hüdai'nin kapısını çalar. Aziz Mahmut Hüdai Hazretleri, elinde daha önce hazırlamış olduğu bir zarf ile kapıya çıkar. Habercinin getirdiği mektubu alırken, elindekini de haberciye verir ve "sultanımızın beklediği cevap burada yazilıdır," der.

Mektubu alan haberci, hemen Padişah'a götürür ve gördüklerini anlatır. Sultan Ahmet Han, mektubu heyecanla okur:

Allah (cc), insan vücudunda sırtı, kâinatta ise toprağı en kuvvetli olarak yarattı. İnsanın sırtı ile toprağın birbirlerine değmesi, bu iki kuvvetin bir araya gelmesi demektir. Böylece, Padişahımızın sırtının toprağa gelmesi ile bu iki kuvvet birleşmiş demektir. Dolayısıyla, bu rüyadan İslâm'ın temsilcisi olan Padişahımızın, küffara karşı zafer kazanacağ 1 anlaşılmaktadır, yazmaktadır.

I. Ahmet Han, bu tabirden çok memnun olur ve işte gördüğüm rüyanın gerçek tabiri budur, der. Bu rüya, istikbâldeki Estergon Kalesi'nin fethini müjdelemiştir. Sultan, hemen Mahmut Hüdai Hazretleri'nin duasını alıp Avusturya üzerine yürümüştür. 


\section{Sonuç}

Tüm bu bilgiler göstermektedir ki Türk kültüründe rüya, insanın zihnine gelen boş bir hayâl ve görüntüden ibaret değil, ilâhî bir mesaj ve uyarı kabul edildiği görülmektedir. Bunda önemli etken rüyaların geçmişin veya geleceğin habercisi olarak görülme durumu ve kişisel hayatta da devlet geleneğinde de kutsallık arz etmesi olarak değerlendirilmesidir. Türk devlet kültüründe rüyalar, üzerinde düşünülmesi ve hatta bu doğrultuda hareket edilmesi gereken bir etken olarak görülmektedir. Oğuz Kağan'dan Sultan Ahmet'e kadar birçok devlet ileri geleni kendi gördükleri ya da sözüne itimat ettikleri bilge kişilerin rüyalarına göre devlet yönetimini yönlendirebilmektedirler.

\section{Kaynakça}

ÂŞIKPAŞAOĞLU AHMED ÂŞIKÎ (1949), Tevârîh-i Âl-i Osman, Osmanlı Tarihleri I, Türkiye Yayınevi, İstanbul.

ÇETíN, H. (2012), Ağaç Motifli Osmanlı Saltanat Rüyasının Tabir İlmi Açısından Değerlendirilmesi, Akademik Bakış, Cilt 5 Sayı 10,Yaz, İstanbul.

GÖKYAY, O. (2001), Dedem Korkud'un Kitabı, İstanbul.

GÜNDÜZ, E. (2009), Divan ve Halk Edebiyatı Sanatçılarına İlham Kaynă̆ı Olan Rüya, Selçuk Üniversitesi Sosyal Bilimler Enstitüsü Dergisi, Konya.

FİNKEL, C. (2007), Rüyadan Imparatorluğa Osmanlı, Çev. Zülal Kılıç, İstanbul. İSLÂM ANSIKKLOPEDİSI (1994), "Devlet" maddesi, TDVY, İstanbul.

İNAN, A. (1991), Makaleler ve İncelemeler, Türk Tarih Kurumu Basımevi, Ankara.

KAYA, D. (2007), Türk Halk Edebiyatı Devlet Geleneği, Akçağ Yayınları, Ankara.

KAYA, G. (2004), Taşlıcalı Yahya Bey'in Şiirlerinde Rüya ve Rüya Tabirleri, İlmi Araştırmalar Dergisi, Sayı:18, İstanbul.

KUZUBAŞ, M. (2007), “ilkellere Ait Anlatılarda Rüya Motifi” Turkish Studies, II/1, İstanbul.

NASKALİ, E. G. (1995), Bozkırdan Bağımsızlı̆̆a Manas, Türk Dil Kurumu Yayınları, Ankara.

NIYAZIOĞLU, A. (2010), “16.yy İstanbul'unda Halveti Sünbüli Şeyhlerinin Rüyaları ve Osmanlı Biyografi Yazıcllığı". Doğu Batı, Osmanlılar III., Doğu Batı Yayınları, Mayıs-Haziran Temmuz, Sayı:53, 21-35, Ankara.

ÖGEL, B. (1993), Türk Mitolojisi, Türk Tarih Kurumu Basımevi, Ankara.

ÖZGÜL, M. K. (2004), Türk Edebiyatında Siyasi Rüyalar, Ankara. 
SEPETÇiOĞLU, N. (1995), Karşılaştırmalı Türk Destanları, İrfan Yayınevi, İstanbul.

SCHIMMEL, A. (2005), Halifenin Rüyaları: İslam'da Rüya ve Rüya Tabiri, Kabalacı Yayınevi, İstanbul.

TEMIZKAN, A, AKTAŞ, E. (2012), “Türk Devlet Geleneğinde İktidarm Meşrulaştırılmasında Rüyanın Kullanımı" Karadeniz Araştırmaları Dergisi, Sayı:33, Bahar, Ankara.

TÜRKÇE SÖZLÜK (2012), TDKY, Ankara.

URAZ, M. (1967), Türk Mitolojisi, Hüsnütabiat Matbaası, İstanbul.

UZUN, G. (2007), Cengiz Aytmatov'un Eserlerinde Falcllk, Kehanet ve Rüya Motifi, Uluslararası Sosyal Araştırmalar Dergisi, Volume 1/3 Bahar, Ordu.

http://www.sultanahmetcami.org/sultan-1-ahmedin-ayasofya--ziyaretleri_h 57.html. Erişim. 25.10.2014 